\title{
Body Horror 2.0
}

\author{
Ian Haig \\ RMIT University \\ 124 Latrobe street, Melbourne, 3000 \\ i.haig@rmit.edu.au
}

\begin{abstract}
Increasingly the contemporary media landscape and the ubiquitous digital screen can be considered as extensions of ourselves. While our bodies are augmented and extended by a variety of contemporary media. The rational, logical and ordered world of the machine operates as the aesthetic opposite to our own bodies, which are messy, irrational and illogical. In this paper I will discuss how technology can remind us and bring us back to the wet reality of our corporeal 'meat' bodies. Body horror 2.0 is a updated version of body horror via the lens of the contemporary media machine. Technology advances at an increasingly rapid rate, while we remain trapped within Darwinian husks of meat we carry around with us called the human body.
\end{abstract}

keywords: VR, bodies, sickness, technology, confrontation

\section{INTRODUCTION}

As one spends more and more time in mediated realities, surrounded by ubiquitous digital screens something odd happens to the reality of our bodies. The contemporary media landscape amplifies this bodily confrontation, and the base level awareness of our own body. It does this through aesthetic opposites - from the rational, clean, ordered, logical world of technology to the irrational, messy, illogical and wet reality of our own bodies.

\section{HORROR BODIES}

I call it Body horror 2.0 a particular form of horror or confrontation where the sophistication of technology amplifies this state of awareness and horror of our primitive meat bodies. Bodies that after all, get sick, age, decay and die, while technology only improves and develops with the next software update. Body horror, or biological horror a genre of the horror film of the 1970s and 1980s was all about body confrontation in a different way, the fear of contagion, of viruses, the fear of sexually transmitted diseases underpinned much of the destruction and degeneration of the body in numerous horror films from the period.

From the body as a spectacular site of destruction and host for the shape shifting alien of The Thing in 1982 to the fear of the sexual parasite in David Cronenberg's Shivers from 1975.

Hal Foster has expressed how increasingly ones own subjecthood is affirmed by the destruction of other bodies on screen. ${ }^{1}$ Technology too confirms our own subjecthood. It is our moist biological bodies on the other end of all those computer screens, mobile devices, digital machines and networks after all.

In the 1990s Hal Foster spoke of the return of the real $^{2}$ and the return to the body in art and a focus on materiality and the body. It is my position that twenty 
years later in 2018 we are seeing the unintended return to the body, but unlike the abject art of the 1990s it is contemporary digital media and systems like VR which has unintentionally amplified an awareness and confrontation of our own body and is largely a by product of various modes of digital media and immersive display technologies.

\section{VR AND CONFRONTATION OF THE BODY}

There is even a recognised condition Virtual reality sickness. The condition occurs when an overload of sensory input occurs in the VR environment, and an increase in stomach awareness, headaches, nausea, sweating, fatigue, disorientation, vomiting and the list goes on. While on one hand the promotional machine for VR presents the technology as a brave new frontier, an idealised and immersive futuristic state of being. On the other hand

VR can connect one with their base level body in surprisingly unintended ways. The unreality of VR at times can very much remind us of the very real reality of our meat bodies.

Dan Edwards has commented on VR and its tendency to induce bodily discomfort:

VR is a world unto itself, a world that feels quite separate from this one - and this feeling is physical, as well as mental. Having my senses and mind in one place, and my body in another, was quite discomforting after a time and I became nauseous and hot, a feeling intensified by viewing four works in a row. For this reason, I find it hard to imagine long-form VR storytelling being a pleasurable experience. $^{3}$

Recently a VR work by Paul McCarthy directly exploited this vast untapped visceral and psychophysical potential of Virtual Reality and notions of bodily confrontation in his piece C.S.S.C Coach Stage Stage Coach VR experiment: Mary and Eve. Increasingly the digital is often cast as immaterial and the binary of the material/immaterial plays out ad nauseum in the contemporary art world. However the McCarthy VR work offered a highly charged and a very real visceral experience, physically making the viewer squirm and importantly cancelling out any notion of digital immateriality. While the digital may be considered to be immaterial it would appear it can have profound material effects on the human body.

Marshall McLuhan clearly embedded the media landscape into the body when he described the evolving electronic age as part of one's nervous system, and went further in describing technological innovations, being extensions of human ability and senses, which alter one's sensory balance. ${ }^{5}$ I can't currently imagine a contemporary technology that literally alters one's sensory balance as much as VR, it alters it to such a degree that at times we feel like throwing up.

As Midas Dekkers' has pointed out the black box of technology is analogous to the black box of the internal body. ${ }^{6}$ While we understand the basic inputs and outputs of technology, the internal structure of the closed technological black box is not so well understood. The deep and dark interior of the body too follows a similar path: we understand the basics of the input and output of the body, but the processes that go on between these states are harder to define.

Since the 1990s the developing world of media art and electronic art: of computers, the web, robotics, virtual reality and games - has seen the focus move away from the corporeal body as a site of visceral materiality to the world of the digital - to the spaces of screen culture, interactivity, immersive virtual worlds, data spheres, information systems, networks and programming.

However occurring at the same time in the mid 1990s abject art and bodily themes of disease, contagion and the abject were making an appearance in the visual arts (by artists like The Chapman Brothers, Marc Quinn, and Paul McCarthy amongst others) In new media art circles however in the 1990s, the opposite was occurring: The utopian narratives of the digital revolution along with virtual reality and the promise of no body and with it, no abjection. As a result, it is my belief that this has 
contributed to a sanitisation of media art culture which positions itself away from the difficult visceral body and in so doing away from the aesthetic of the messy reality of the corporeal human body, even though those same digital technologies used by media artists create the very conditions for the confrontation and increased awareness of the body, VR being one such example. Body horror

In 1977 Michel Treisman put forward the theory which suggested nausea from motion sickness is a result of an evolutionary adaption to protect ourselves from being poisoned. ${ }^{4}$ Treisman suggested that certain toxins when ingested can mess with the vestibular system, if you ingest poison the automatic bodily reaction is to eject the offending poison through vomiting. Increased body awareness and nausea from some VR experiences is perhaps not simply an annoying by-product of VR, but perhaps a new kind of untapped technologically enabled somatic subjectivity. The evolution of advanced technologies causing us to activate our evolutionary brain or another way to consider it: VR poisoning.

Some of our machines are making us feel sick, so it would appear the reminder of the inconvenient reality of the human body is not as remote from the digital media landscape as we would like to believe it is. While I propose our technologies remind us of our meat bodies, however this confrontation of the body simultaneously sees a strange denial. The denial to everyday base level bodily functions like shitting is also a reminder of the body but we are also in denial of the act of shitting, shitting after all is rotting organic matter, a reminder of what our body becomes in death, so the denial of shitting is perhaps a denial of death. While our digital machines force us to reconcile the fact that we are living, breathing, and indeed shitting beings. No matter how gloriously sophisticated our technologies evolve, as a species our shit still stinks.

Body 2.0 is therefore a corrective to the denial and removal of the base level body within media art culture. It s an updated version of body horror via the the lens of contemporary media.
The rapid changes in contemporary technologies remind us of, and amplify, our own physical bodies in ways that have not previously existed prior to the omnipresence of the contemporary media sphere. New and emergent technologies are imbued with a dominant paradigm of progress and advancement that is often presented within a sanitised aesthetic and which highlights and contrasts with our actual, visceral bodies. Media art practices which utilise these technologies tend to follow suit, presenting the viewer with a body that is removed from the corporeal, its visceral materiality, and related aesthetics of disgust, repulsion and body horror.

While technology has brought about an unprecedented change in how we deal with the world around us, the sophistication of the newmedia landscape has seen our technologies evolve but our bodies remain stagnant and sedentary. Our bodies are not evolving at the same rate as the media that surrounds us. Our machines may be advancing to dizzying new technological heights but, in terms of evolution, we will always remain trapped within our moist bodies.

\footnotetext{
'Foster, H (1996) Return of the Real, MIT Press, US

${ }^{2}$ Foster, H (1996) Op. cit.
}

3 Edwards, D. (2017) vr-at-miff-a-world-apart http://www.realtime.org.au/vr-at-miff-a-world-apart (viewed $18^{\text {th }}$ March 2018)

4 Treisman, M. (1977) Motion sickness: an evolutionary hypothesis http://science.sciencemag.org/content/197/4302/49 (viewed $20^{\text {th }}$ March 2018)

${ }^{5}$ McLuhan, M and Bruce Powers (1989) The Global Village: World Life and Media in the $21^{\text {st }}$ century, Oxford university press, UK

${ }^{6}$ Dekkers, M. (2014) The Story of Shit, Text Publishing, Australia 